\title{
Serum Presepsin Levels in Patients with Decompensated Heart Failure
}

\author{
İsmail Bıyık¹, Fatma Nihan Turhan Çağlar², Nilgün Işıksaçan³ ${ }^{3}$ Mustafa Hakan Şahin², \\ Dilay Karabulut ${ }^{2}$, Fahrettin Katkat ${ }^{4}$, Faruk Aktürk ${ }^{2}$
}

\footnotetext{
1) Department of Cardiology, Usak University, School of Medicine, Education and Research Hospital, Usak, Turkey

2) Department of Cardiology, Bakirkoy Dr. Sadi Konuk Education and Research Hospital, Istanbul, Turkey

3) Department of Biochemistry, Bakirkoy Dr. Sadi Konuk Education and Research Hospital, Istanbul, Turkey

4) Department of Cardiology, Bagcilar Education and Research Hospital, Istanbul, Turkey
}

\begin{abstract}
Objective: Recently, the soluble CD14 subtype; presepsin (PSP) has been suggested as a reliable marker for systemic inflammation, which has not been studied in decompensated heart failure (DHF) up to date. Our aim was to investigate plasma PSP levels and its diagnostic ability in patients with DHF.

Methods: Fifty patients with DHF and 51 controls without HF were included in our study. Besides routine clinical and laboratory data, N-terminal prohormone of brain natriuretic peptide (NT-pro BNP) and PSP levels were measured in blood samples of all the participants.

Results: PSP levels were significantly higher in patients with DHF than controls $(1107.98 \pm 1001.15$ vs. $540.47 \pm 526.9$ $\mathrm{pg} / \mathrm{mL}, \mathrm{p}=0.001$ ). Cut-off value for PSP was $442 \mathrm{pg} / \mathrm{mL}$ to detect HF with $76 \%$ sensitivity, $62.7 \%$ specificity, $66.7 \%$ positive predictive value and $72.7 \%$ negative predictive value (CI: $0.975-1.000)$. The diagnostic accuracy of PSP for DHF was not superior to that of NT-pro BNP (AUC: 0.99 vs. 0.74)
\end{abstract}

Conclusions: This preliminary study reveals that PSP levels are significantly elevated in patients with DHF but the diagnostic power of PSP for DHF is lower than NT-pro BNP. PSP may be a new marker for DHF.

Keywords: Decompensated heart failure, presepsin, inflammation 


\section{Introduction}

Decompensated heart failure (HF) is a clinical syndrome caused by many conditions resulting in reduced cardiac output. ${ }^{(1)}$ There are many pathophysiological mechanisms of HF besides cardiovascular pathologies, and inflammation is one of them..$^{(1)}$ The correlation between $\mathrm{C}$ - reactive protein (CRP) and the severity and prognosis of HF is a good example for the role of inflammation in the development of HF.(1) Besides CRP many other inflammatory markers such as cytokines, tumor necrosis factor 6 (TNF-6), interleukin 6 (IL6), oxidative stress markers and leukocytosis have been shown to be involved in the onset and development of HF. ${ }^{(1,3)}$ Recently, natriuretic peptides have been used for screening, diagnosis and prognosis of acute HF. ${ }^{(1)}$

However, their plasma levels are affected by some clinical situations such as renal failure and they may not be reflecting all of the pathophysiologies underlying HF. ${ }^{(1)}$ Presepsin (PSP) is a novel inflammatory marker. ${ }^{(4)}$ Several clinical studies suggest PSP as an acute phase reactant similar to CRP. ${ }^{(5)}$ Monocytes, macrophages and neutrophils express a cluster of differentiation (CD) surface glycoprotein named CD14. ${ }^{(6)}$ CD14 forms a circulating soluble subtype after activated by plasma proteases which is named as SCD14-ST, also known as PSP. ${ }^{(6)}$ Although the diagnostic power, prognostic value and mortality predictive capacity of PSP have been widely evaluated and accepted in sepsis, almost no publications about the association between PSP and heart failure has been available in literature to date. ${ }^{(4,7,8)}$. Our aim in this study was to investigate plasma PSP levels and its diagnostic ability in patients with acute decompensated HF.

\section{Methods}

\section{Study population}

This observational comparative study was conducted in a tertiary referral center. In this study, we used the methods of our previous study. ${ }^{(9)}$ Fifty patients admitted to coronary care unit with acute decompensated $\mathrm{HF}$ and 51 age-matched control group patients without $\mathrm{HF}$ as verified by echocardiography were enrolled in this study. The study protocol was approved by the local ethics committee review board. The study complied with the Declaration of Helsinki and informed written consent was obtained from all patients included in this study. The patient group was consisted of patients admitted to coronary care unit with symptoms and signs of acutely decompensated HF (New York Heart Association Classification 2 to 4 ) as in described by related European Society of Cardiology guideline and left ventricular ejection fraction lower than $40 \%$ as shown by echocardiography. ${ }^{(10)}$ We included both de novo and previously known HF patients regardless of the etiology. We were excluded some specific cardiomyopathy phenotypes such as hypertrophic cardiomyopathy, peripartum cardiomyopathy and alcoholic cardiomyopathy.

Control group was consisted of age matched volunteers. All clinical available data at the time of initial visit were collected by two cardiologists from the medical records of each patient. Patients with diabetes mellitus and hypertension were not excluded from the study. ${ }^{(9)}$ The glomerular filtration rate was estimated by using the Modification of Diet in Renal Disease (MDRD) equation at admission. Body mass index (BMI) was calculated due to World Health Organization criteria. ${ }^{(1)}$ Patients with known inflammatory disease, serious valvular disease, uncontrolled hypertension, serious hepatic failure, fever, acute or chronic infection, receiving antibiotic therapy, muscle aches, immunoproliferative disease, osteoporosis, rheumatic disease, cancer, younger than 18 years old and older than 70 years old, estimated glomerular filtration rate (eGFR) $<60 \mathrm{~mL} / \mathrm{min} / 1.73 \mathrm{~m} 2$ were excluded. ${ }^{(9)}$

\section{Laboratory measurements}

Blood samples for PSP and other biochemical measurements were taken from the patients once the diagnosis of decompensated HF was made and volunteers in the control group. All of the laboratory measurements of the study participants consisting of white blood cell count (WBC), high sensitive CRP (hsCRP) and creatinine were performed. Blood samples for PSP measurement were obtained by vein puncture into ethylene diamine tetra acetic acid (EDTA) blood collection tubes without additives and immediately centrifuged at 2500 rpm for 10 minutes. ${ }^{(9)}$ The serum was collected and stored at $-80{ }^{\circ} \mathrm{C}$ until analysis up to six months. The samples were thawed out once. All the assays were performed according to the manufacturer's recommendations with the Pathfast ${ }^{\circledR}$ immunoassay analytical 
system (Progen Biotechnik GmbH, Germany and Mitsubishi Chemical Medience Corporation, Japan) using plasma from EDTA tubes. ${ }^{(9)}$ Heparinized whole blood samples were centrifuged at $1000 \mathrm{rpm}$ for 5 minutes and NT-ProBNP measurements were performed using chemiluminescence method (Cobas e411, Roche Diagnostics, Basel, Switzerland). ${ }^{(9)}$ Following centrifugation at $1000 \mathrm{rpm}$ for 10 minutes of plain tubes, creatinine and hsCRP levels were measured according to the manufacturer's recommendations with using related methods (Cobas c501, Roche Diagnostics, Basel, Switzerland). ${ }^{(9)}$

\section{Statistical analysis}

Number Cruncher Statistical system (NCSS) (Kaysville, Utah, USA 2007) programme was used for statistical analysis. Study data were analyzed using descriptive statistical methods such as mean, standard deviation, median, frequency, ratio, minimum and maximum. Normally distributed quantitative data were analyzed by Student $t$ test, and non-normally distributed data were analyzed by Mann Whitney U test. Comparisons of qualitative data were analyzed by Yates' Continuity Correction test. ${ }^{(9)}$

Diagnostic screening tests (sensitivity, specificity, positive predictive value, negative predictive value) and ROC (Receiver Operating Curve) curve test were performed for determining PSP and NT-proBNP cut-off values. Spearman's rank correlation was made to test the association of PSP with other laboratory parameters. Two tailed $\mathrm{p}$ values lower than 0.01 with $99 \%$ confidence level and lower than 0.05 with $95 \%$ confidence level were accepted as statistically significant. ${ }^{(9)}$

\section{Results}

Fifty patients with HF [27 (54\%) male and 23 (46\%) female)] and 51 voluntary controls [20 (39.2\%) male and $31(60.8 \%)$ female)] were included in the analysis. Baseline characteristics and laboratory findings are given in Table 1. Mean age, BMI, smoking and medical history were similar among groups. Left ventricular ejection fraction (LVEF) measurements were significantly lower in HF group than controls as expected ( $30 \pm 9 \%$ vs. $63 \pm 4 \%, \mathrm{p}=0.001)$. PSP levels were significantly higher in HF group than controls $(1107.9 \pm$
$1001.1 \mathrm{pg} / \mathrm{mL}$ vs. $540.4 \pm 526.9 \mathrm{pg} / \mathrm{mL}, \mathrm{p}=0.001)$. NT-proBNP levels were higher in HF group than control group as predicted (11227.2 pg / $\mathrm{mL} \pm 11443.2 \mathrm{vs.}$ $174.1 \pm 207.9 \mathrm{pg} / \mathrm{mL}, \mathrm{p}=0.001)$. Levels of hsCRP did not show significant difference among groups (4.65 \pm $10.9 \mathrm{mg} / \mathrm{L}$ vs. $3.9 \pm 4.1 \mathrm{mg} / \mathrm{L}, \mathrm{p}=0.239)$. WBC count was also similar among groups $(9.13 \pm 2.97$ vs. $9.01 \pm$ $3.24109 / \mathrm{L}, \mathrm{p}=0.58$ ). Likewise, creatinine levels were similar among groups.

Diagnostic screening test and ROC curve analysis for determining cut-off for NT-proBNP and PSP are given in Table 2. Cut-off value for NT-proBNP was $727 \mathrm{pg} / \mathrm{mL}$ to detect HF with $98 \%$ sensitivity, $96 \%$ specificity, $96.1 \%$ positive predictive value and $98 \%$ negative predictive value (AUC: 99.1\%, SD: 0.008) and cut-off value for PSP was $472 \mathrm{pg} / \mathrm{mL}$ to detect HF with $76 \%$ sensitivity, $62.7 \%$ specificity, $66.7 \%$ positive predictive value and $72.7 \%$ negative predictive value (AUC: $73.8 \%$, SD: 0.049). PSP levels were not correlated with NT-proBNP, hsCRP and WBC ( $p>0.05)$ (Table 3). The diagnostic value of PSP levels to diagnose HF was statistically lower than NT-proBNP ( $p=$ 0.001) (Table 2).

\section{Discussion}

In this study, we investigated the diagnostic ability of PSP in patients with decompensated HF. The results revealed that PSP was significantly increased in patients with decompensated HF compared to controls, but it was not correlated with NT-proBNP, hsCRP and WBC, and the diagnostic power of PSP to diagnose decompensated HF was statistically lower than NT-proBNP. Various cardiac and non-cardiac disorders may cause HF by different pathophysiological mechanisms. ${ }^{(1,12)}$ Systemic inflammation plays a role in all steps of HF and could be the reason of HF onset or impairment of a previously stable HF. ${ }^{(1,12,13)}$

It is widely accepted that inflammatory mediators may deteriorate cardiac function Leukocytosis and monocyte or macrophage levels are correlated in postmyocardial infarction patients with HF. ${ }^{(3)} \mathrm{Up}$ to date, many inflammatory biomarkers have been identified to recognize and to make risk stratification in patients with HF. ${ }^{(1,13)}$ Among them, hsCRP, TNF" $\alpha$ " and IL6 
Table 1. Demographic features and laboratory findings of HF and control group

\begin{tabular}{|c|c|c|c|c|}
\hline & & $\begin{array}{l}\text { Patient group } \\
\quad(n=50)\end{array}$ & $\begin{array}{l}\text { Control group } \\
\qquad(n=51)\end{array}$ & $p$ value \\
\hline Age (years) & Mean \pm SD & $69.1 \pm 12.2$ & $65.6 \pm 10.3$ & a0 0.110 \\
\hline \multirow{2}{*}{ Sex $n(\%)$} & Male & $27(54.0)$ & $20(39.2)$ & \multirow{2}{*}{${ }^{\circ} 0.197$} \\
\hline & Female & $23(46.0)$ & $31(60.8)$ & \\
\hline \multirow{3}{*}{ BMI (kg/m2) } & Mean \pm SD & $28.38 \pm 3.27$ & $27.33 \pm 3.18$ & \multirow{3}{*}{${ }^{\mathrm{b}} 0.112$} \\
\hline & Min-Max & $20-36$ & $21-33$ & \\
\hline & (Median) & (29) & $(27.5)$ & \\
\hline Smoking & & $24(48.0)$ & $32(66.7)$ & ${ }^{\mathrm{c}} 0.615$ \\
\hline Hypertension n (\%) & & $27(54.0)$ & $22(43.1)$ & ${ }^{\mathrm{c}} 0.372$ \\
\hline Diabetes n (\%) & & $11(22.0)$ & $10(19.6)$ & ${ }^{c} 0.959$ \\
\hline Hyperlipidemia n (\%) & & $24(48,0)$ & $25(49,0)$ & b0,918 \\
\hline History of CVA n (\%) & & $1(2.0)$ & $0(0)$ & d0.495 \\
\hline \multirow{3}{*}{ EF } & Mean \pm SD & $0.30 \pm 0.09$ & $0.63 \pm 0.04$ & \multirow{3}{*}{${ }^{\mathrm{a}} 0,001^{\text {**}}$} \\
\hline & Min-Max & $0.15-*-0.45$ & $0.52-0.7$ & \\
\hline & (Median) & $(0.3)$ & $(0.6)$ & \\
\hline \multirow{3}{*}{ NT-proBNP (pg/mL) } & Mean \pm SD & $11227.2 \pm 11443.2$ & $174.1 \pm 207.9$ & \multirow{3}{*}{${ }^{\mathrm{a}} 0.001^{* \star}$} \\
\hline & Min-Max & $100-35000$ & $20-1050$ & \\
\hline & (Median) & $(6610)$ & (85) & \\
\hline \multirow{3}{*}{ Presepsin (pg/mL) } & Mean \pm SD & $1107.9 \pm 1001.1$ & $540.4 \pm 526.9$ & \multirow{3}{*}{${ }^{a} 0.001^{* *}$} \\
\hline & Min-Max & $147-5529$ & $111-2722$ & \\
\hline & (Median) & $(684)$ & (341) & \\
\hline \multirow{3}{*}{ hsCRP (mg/dL) } & Mean \pm SD & $4.65 \pm 10.9$ & $3.99 \pm 4.18$ & \multirow{3}{*}{${ }^{\mathrm{a}} 0.097$} \\
\hline & Min-Max & $0.1-75.5$ & $0.2-17.8$ & \\
\hline & (Median) & (1.3) & $(2.6)$ & \\
\hline \multirow{3}{*}{ Creatinine (mg/dL) } & Mean \pm SD & $0.78 \pm 0.17$ & $0.87 \pm 0.25$ & \multirow{3}{*}{${ }^{\mathrm{a}} 0.056$} \\
\hline & Min-Max & $0.42-1.03$ & $0.41-1.13$ & \\
\hline & (Median) & $(0.68)$ & $(0.74)$ & \\
\hline \multirow{3}{*}{ WBC (x109/L) } & Mean \pm SD & $9.13 \pm 2.97$ & $9.01 \pm 3.24$ & \multirow{3}{*}{${ }^{\circ} 0.587$} \\
\hline & Min-Max & $5-15.9$ & $5-17.6$ & \\
\hline & (Median) & (8.5) & (8.3) & \\
\hline
\end{tabular}

a Student $t$ test, ${ }^{b}$ Paired chi square test, ' Yates Continuity Correction Test, a Fisher's Exact test

SD; standard deviation, BMI; body mass index, CVA; cerebrovascular accident, EF; ejection fraction, NT-proBNP; N-terminal prohormone of brain natriuretic peptide, $\boldsymbol{h s C R P ;}$;igh sensitive $C$ reactive protein, WBC; white blood cell, ${ }^{* *} p<0,01$ 
are the mostly studied ones..$^{(1,12,13)}$ However, traditional laboratory tests could not efficiently reflect the progression of HF. ${ }^{(12)}$ One of the receptors of monocyte / macrophage specific cluster of differentiation and lipopolysaccharide (LPS) / LPS-binding protein (LBP) complexes is CD14. ${ }^{(4,7)}$ Cleaved $\mathrm{N}$ - terminal fragment of CD14 is called PSP glycoprotein. ${ }^{(4)}$ PSP normally exist in healthy people's blood for a certain amount and increase in response to inflammation. ${ }^{(4,7)}$

We showed median serum PSP level $341 \mathrm{pg} / \mathrm{mL}$ ranging between 111 and $2722 \mathrm{pg} / \mathrm{mL}$ in the control group. This result is consistent with other studies which mostly report PSP levels as 55 - 600 pg / mL. ${ }^{(14,15)}$ The wide range of PSP levels among studies may be due to the selection bias of the subjects or the method of PSP measurement. ${ }^{(2,16)}$ We measured PSP with chemiluminescent enzyme immunoassay method which is the most used method in other studies.

It has been demonstrated that increased PSP levels are correlated with the existence, severity and prognosis prediction of systemic inflammation. ${ }^{(4,17,18)}$ Masson et al demonstrated that PSP levels were higher in patients died as a result of severe sepsis or septic shock than survivors, and suggested to measure PSP for early risk stratification in these patients. ${ }^{(18)}$

The roles of PSP in different clinical situations have also been evaluated. ${ }^{(7,14,19)}$ Klouche et al showed the usefulness of PSP in patients with severe sepsis, septic shock and severe community-acquired pneumonia and found that the level of PSP increase was different among subgroups.${ }^{(19)}$ Endo et al stated that PSP is one of the most predictive markers of sepsis and is more valuable than blood culture. ${ }^{(20)}$ Shozushima et al reported that PSP is comparable to procalcitonin for the diagnosis of infections and clinical specificity of PSP is much higher than procalcitonin. ${ }^{(21)}$ Hou et al reported that PSP is a sensitive predictor and a useful monitoring marker in patients with systemic inflammation and nephrolithiasis. ${ }^{(7)}$ Olad et al measured PSP in patients with chemotherapy induced severe neutropenia and demonstrated that PSP was significantly higher in patients with culture positive infections but was not sensitive enough to detect culture negative bacteremia. ${ }^{(8)}$

In the present study, we demonstrated significantly higher PSP levels in patients with acute decompensated HF than the control group $(p=0.001)$. Similarly, Popov et al evaluated the prognostic value of PSP in patients operated for acquired heart diseases and revealed that PSP levels were increased in patients with acute HF and acute coronary syndrome without infection. ${ }^{(22)}$

In our study, median PSP level was $684 \mathrm{pg} / \mathrm{mL}$ ranging from 147 to $5529 \mathrm{pg} / \mathrm{mL}$ in the patient group. Liu et al declared median PSP levels as $787 \mathrm{pg} / \mathrm{mL}$ for severe sepsis and $1084 \mathrm{pg} / \mathrm{mL}$ for septic shock in an emergency department. ${ }^{(23)}$ Behnes et al reported diagnostic PSP cutoffs as $\geq 530 \mathrm{pg} / \mathrm{mL}$ for sepsis, $\geq 600 \mathrm{pg} /$ $\mathrm{mL}$ for severe sepsis and $\geq 700 \mathrm{pg} / \mathrm{mL}$ for septic shock (89\% sensitivity, AUC: 0.77). ${ }^{(5)}$ Diagnostic cutoff value of PSP was $\geq 472 \mathrm{pg} / \mathrm{mL}$ for HF in our study. Our results showed that PSP had the acceptable pooled sensitivity (0.76) and pooled specificity (0.63). Accordingly, the AUC was 0.74, indicating that the PSP had a moderate diagnostic efficiency. Zheng et al's meta-analysis reported the results of 8 studies conducted on the pa-

Table 2. Diagnostic screening tests and ROC curve analysis for NT pro BNP and Presepsin

\begin{tabular}{|c|c|c|c|c|c|c|c|c|}
\hline & \multicolumn{5}{|c|}{ Diagnostic Scan } & \multicolumn{2}{|c|}{ ROC Curve } & \multirow{2}{*}{$\begin{array}{c}p \\
\text { value }\end{array}$} \\
\hline & $\begin{array}{l}\text { Cut- } \\
\text { off }\end{array}$ & Sensitivity & Specificity & $\begin{array}{c}\text { Positive } \\
\text { Predictive } \\
\text { Value }\end{array}$ & $\begin{array}{c}\text { Negative } \\
\text { Predictive } \\
\text { Value }\end{array}$ & AUC & $\begin{array}{l}\text { 95\% Con- } \\
\text { fidence } \\
\text { Interval }\end{array}$ & \\
\hline NT-proBNP & $\geq 727$ & 98.0 & 96.08 & 96.1 & 98 & 0.991 & $0.975-1.000$ & 0.001 \\
\hline Presepsin & $\geq 472$ & 76.0 & 62.75 & 66.7 & 72.7 & 0.738 & $0.642-0.835$ & 0.001 \\
\hline
\end{tabular}


tients with severe systemic inflammation and demonstrated the sensitivity range of PSP as $0.71-0.93$ and the specificity range as $0.60-0.86 .{ }^{(17)}$ Our study results are consistent with these ranges. PSP levels are affected by kidney function because of its low molecular weight. ${ }^{(14)}$

PSP is filtered by the glomeruli, reabsorbed and catabolized by proximal tubular cells. ${ }^{(14)}$ Nagata et al studied PSP levels in patients with different stages of chronic kidney disease and demonstrated that PSP levels increase as eGFR decrease. ${ }^{(14)}$ Behnes et al. showed the correlation between PSP and creatinine levels and the number of days on renal replacement therapy in patients in intensive care unit. ${ }^{(5)}$ For that reason, we did not include the patients with eGFR lower than $60 \mathrm{~mL} /$ $\min / 1.73 \mathrm{~m} 2$ in the study. We did not include patients over 70 years old based on the study of Chenevier-Gobeaux et al. ${ }^{(24)}$ They revealed significantly increased PSP levels in patients older than 70 years old compared to patients younger than 70 years old. ${ }^{(24)}$

Biochemical and hematological markers are important predictors in development and diagnosis of cardiovascular diseases $(25,26)$. In our previous study, we also reported that PSP levels were significantly elevated in acute ST elevation myocardial infarction patients together with high sensitivity troponins, which may be a novel supporting marker for acute myocardial infarction. ${ }^{(9)}$ It has recently been reported that elevated

Table 3. Univariate correlations of presepsin with other markers

\begin{tabular}{|c|c|c|c|}
\hline & & \multicolumn{2}{|c|}{ PSP } \\
\hline & & Patients & Controls \\
\hline \multirow{2}{*}{ NT-proBNP } & $r$ & 0,021 & 0,128 \\
\hline & $\mathrm{p}$ & 0,884 & 0,372 \\
\hline \multirow{2}{*}{ hsCRP } & $r$ & 0,055 & $-0,175$ \\
\hline & $p$ & 0,702 & 0,220 \\
\hline \multirow[t]{2}{*}{ WBC } & $r$ & 0,126 & $-0,027$ \\
\hline & $p$ & 0,383 & 0,851 \\
\hline \multicolumn{4}{|c|}{$\begin{array}{l}r \text { : Spearman's Correlation Coefficient, NT-proBNP; } N \\
\text { terminal prohormone of brain natriuretic peptide, hsCRP; } \\
\text { high sensitive C reactive protein, WBC; white blood cell }\end{array}$} \\
\hline
\end{tabular}

preoperative plasma presepsin concentration is an independent predictor of postoperative mortality in cardiac surgery patients and PSP is a stronger predictor than other powered markers such as procalcitonin, NT-proBNP and cystatin C. ${ }^{(27)}$ We also investigated PSP levels in well-controlled hypertensive patients and compared to healthy controls. ${ }^{(28)}$ The results revealed that PSP levels were significantly lower in patients with wellcontrolled hypertension than healthy controls, which may be related to anti-inflammatory effects of antihypertensive agents. ${ }^{(28)}$

We also compared PSP with NT-proBNP being a biomechanical stress marker for HF recognized by the related guidelines. ${ }^{(10)}$ A large body of evidence from clinical and experimental studies demonstrated NTproBNP as a precise mortality and morbidity predictor for HF. ${ }^{(29,30)}$ Although PSP levels were significantly increased in patients with HF, the results were not correlated with NT-proBNP levels in the present study.

Moreover the sensitivity, specificity and predictive value of PSP to recognize HF were lower than NTproBNP. The diagnostic accuracy of PSP in HF was not superior to that of NT-proBNP. Our study does have some limitations. This study is a small, single centered, observational study. Biomarker follow-up during $\mathrm{HF}$ setting is of fundamental clinical importance. We were able to measure PSP once, so we may have missed the biological intra-individual variation over time. We were not able to compare PSP levels and NYHA class because the number of patients was not enough. Despite above limitations, the strength of this study comes from that it has revealed increased PSP levels in patients with decompensated HF up to date.

\section{Conclusions}

This preliminary study reveals that PSP levels are significantly elevated in patients with acute decompensated HF but the diagnostic power of PSP for decompensated HF is lower than NT-pro BNP. PSP may be a new marker for decompensated HF. Large scale studies are needed to reveal the importance of PSP in the diagnosis and prognosis of HF. 


\section{References}

1. Dupuy AM, Curinier C, Kuster N, Huet F, Leclercq F, Davy JM, Cristol JP, Roubille F. Multi-Marker Strategy in Heart Failure: Combination of ST2 and CRP Predicts Poor Outcome. PLoS One. 2016; 11: e0157159.

2. Gullestad L, Kjekshus J, Damås JK, Ueland T, Yndestad A, Aukrust P. Agents targeting inflammation in heart failure. Expert Opin Investig Drugs. Expert Opin Investig Drugs. 2005; 14: 557-566.

3. Swirski FK, Nahrendorf M. Leukocyte behavior in atherosclerosis, myocardial infarction, and heart failure. Science. 2013; 339: 161-166.

4. Ishikura H, Nishida T, Murai A, Nakamura Y, Irie Y, Tanaka J, Umemura T. New diagnostic strategy for sepsis-induced disseminated intravascular coagulation: a prospective single-center observational study. Crit Care. 2014; 18: R19.

5. Behnes M, Bertsch T, Lepiorz D, Lang S, Trinkmann F, Brueckmann M, Borggrefe M, Hoffmann U. Diagnostic and prognostic utility of soluble CD 14 subtype (presepsin) for severe sepsis and septic shock during the first week of intensive care treatment. Crit Care. 2014; 18: 507.

6. Ovayolu A, Özdamar Ö, Gün İ, Arslanbuga CY, Sofuoğlu K, Tunalı G, Topuz S. Can blood or follicular fluid levels of presepsin predict reproductive outcomes in ART; a preliminary study. Int J Clin Exp Med 2015; 8: 7983-7988.

7. Hou YS, Wang H, Chen H, Wu LF, Lu LF, He Y. Pathfast presepsin assay for early diagnosis of systemic inflammatory response syndrome in patients with nephrolithiasis. Biomed Res Int. 2015; 2015: 792572.

8. Olad E, Sedighi I, Mehrvar A, Tashvighi M, Fallahazad V, Hedayatiasl A, Esfahani H. Presepsin (scd14) as a marker of serious bacterial infections in chemotherapy induced severe neutropenia. Iran J Pediatr. 2014; 24: 715-722.

9. Caglar FNT, Isiksacan N, Biyik I, Opan S, Cebe H, Akturk IF. Presepsin (sCD14-ST): could it be a novel marker for the diagnosis of ST elevation myocardial infarction? Arch Med Sci Atheroscler Dis. 2017; 2: e3-e8.

10. Ponikowski P, Voors AA, Anker SD, Bueno H, Cleland JG, Coats AJ, Falk V, González-Juanatey JR, Harjola VP, Jankowska EA, et al. Authors/Task Force Members; Document Reviewers. 2016 ESC Guidelines for the diagnosis and treatment of acute and chronic heart failure: The Task Force for the diagnosis and treatment of acute and chronic heart failure of the European Society of Cardiology (ESC). Developed with the special contribution of the Heart Failure Association (HFA) of the ESC. Eur J Heart Fail. 2016; 18: 891-975.

11. WHO. Physical Status: the use and interpretation of anthropometry. Report of a WHO Expert Committee Technical Report Series, No 854. Geneva: World Health Organization; 1995.

12. Huang Y, Lin Y, Zhang S, Wang Z, Zhang J, Chang C, Liu L, Ji Q, Liu X. Circulating Omentin-1 Levels Are Decreased in Dilated Car- diomyopathy Patients with Overt Heart Failure. Dis Markers. 2016; 2016: 6762825 .

13. Pearson TA, Mensah GA, Alexander RW, Anderson JL, Cannon RO, Criqui M, Fadl YY, Fortmann SP, Hong Y, Myers GL, Rifai N, Smith SC Jr, Taubert K, Tracy RP, Vinicor F. Markers of inflammation and cardiovascular disease: application to clinical and public health practice: A statement for healthcare professionals from the Centers for Disease Control and Prevention and the American Heart Association. Circulation 2003; 107: 499-511.

14. Nagata T, Yasuda Y, Ando M, Abe T, Katsuno T, Kato S, Tsuboi N, Matsuo S, Maruyama S. Clinical impact of kidney function on presepsin levels. PLoS One. 2015; 10: e0129159.

15. Giavarina D, Carta M. Determination of reference interval for presepsin, an early marker for sepsis. Biochem Med (Zagreb) 2015; 25: 64-68.

16. Zheng Z, Jiang L, Ye L, Gao Y, Tang L, Zhang M. The accuracy of presepsin for the diagnosis of sepsis from SIRS: a systematic review and meta-analysis. Ann Intensive Care 2015; 5: 48.

17. Zou Q, Wen W, Zhang X. Presepsin as a novel sepsis biomarker. World J Emerg Med 2014; 5: 16-19.

18. Masson S, Caironi P, Spanuth E, Thomae R, Panigada M, Sangiorgi G, Fumagalli R, Mauri T, Isgrò S, Fanizza C, Romero M, Tognoni G, Latini R, Gattinoni L; ALBIOS Study Investigators. Presepsin (soluble CD14 subtype) and procalcitonin levels for mortality prediction in sepsis: data from the Albumin Italian Outcome Sepsis Trial. Crit Care. 2014; 18: R6.

19. Klouche K, Cristol JP, Devin J, Gilles V, Kuster N, Larcher R, Amigues L, Corne P, Jonquet O, Dupuy AM. Diagnostic and prognostic value of soluble CD14 subtype (Presepsin) for sepsis and community-acquired pneumonia in ICU patients. Ann Intensive Care. 2016; 6: 59.

20. Endo S, Suzuki Y, Takahashi G, Shozushima T, Ishikura H, Murai A, Nishida T, Irie Y, Miura M, Iguchi H, Fukui Y, Tanaka K, Nojima T, Okamura Y. Usefulness of presepsin in the diagnosis of sepsis in a multicenter prospective study. J Infect Chemother 2012; 18: 891-897.

21. Shozushima T, Takahashi G, Matsumoto N, Kojika M, Okamura Y, Endo S. Usefulness of presepsin (sCD14-ST) measurements as a marker for the diagnosis and severity of sepsis that satisfied diagnostic criteria of systemic inflammatory response syndrome. J Infect Chemother. 2011; 17: 764-769.

22. Popov D, Plyushch M, Ovseenko S, Abramyan M, Podshchekoldina O, Yaroustovsky M. Prognostic value of sCD14-ST (presepsin) in cardiac surgery. Kardiochir Torakochirurgia Pol. 2015; 12: 30-36.

23. Liu B, Chen YX, Yin Q, Zhao YZ, Li CS. Diagnostic value and prognostic evaluation of Presepsin for sepsis in an emergency department. Crit Care 2013; 17: R244. 
24. Chenevier-Gobeaux C, Trabattoni E, Roelens M, Borderie D, Claessens YE. Presepsin (sCD14-ST) in emergency department: the need for adapted threshold values? Clin Chim Acta 2014; 427: 34-36.

25. Isiksacan N, Biyik I, Kasapoglu P, Koser M, Turhan Caglar FN, Kocamaz N, Akturk IF. Increased risk of cardiovascular disease may be starting in childhood: $25 \mathrm{OH}$ vitamin D levels in Turkish Children. EJCM 2018; 06 (1): 1-6. Doi: 10.15511/ejcm.18.00101.

26. Erturk M, Turhan Caglar FN, Biyik I, Isiksacan N, Yazan S, Yıldırım MR, Baycan OF, Ozalp B, Karakurt H. Correlations between hematological indicators and other known markers in acute coronary syndromes. EJCM 2017; 05 (4): 67-74. Doi: 10.15511/ejcm.17.00467.

27. Bomberg H, Klingele M, Wagenpfeil S, Spanuth E, Volk T, Sessler DI, Schäfers HJ, Groesdonk HV. Presepsin (sCD14-ST) Is a Novel Marker for Risk Stratification in Cardiac Surgery Patients. Anesthesiology.
2017; 126: 631-642.

28. Biyik I, Caglar FNT, Isiksacan N, Kocamaz N, Kasapoglu P, Gedikbasi A, Akturk F. Serum Presepsin Levels Are Not Elevated in Patients with Controlled Hypertension. Int J Hypertens. 2018 Feb 8;2018:8954718. doi: $10.1155 / 2018 / 8954718$.

29. Sudharshana Murthy KA, Ashoka HG, Aparna AN. Evaluation and comparison of biomarkers in heart failure. Indian Heart J. 2016; 68 Suppl 1: S22-28.

30. Shah MR, Hasselblad V, Tasissa G, Christenson RH, Binanay C, O'Connor CM, Ohman EM, Stevenson LW, Califf RM. Rapid assay brain natriuretic peptide and troponin I in patients hospitalized with decompensated heart failure (from the Evaluation Study of Congestive Heart Failure and Pulmonary Artery Catheterization Effectiveness Trial). Am J Cardiol. 2007; 100: 1427-1433.
Received: 28/04/2018

Accepted: 30/05/2018

Published: 05/06/2018

Disclosure and conflicts of interest:

The authors declare no conflict of interest.

\section{Corresponding author:}

Ismail Biyık

Mail: ismailbiyikmd@yahoo.com 